\title{
Spiritualitas dan Hak Asasi Manusia
}

\section{Oleh: Kautsar Azhari Noer \\ Kaustar@uinjkt.ac.id}

\begin{abstract}
Abstrak : Bila kualitas spiritual manusia baik, maka kualitas kehidupan manusia juga baik. Bila kualitas spiritual manusia buruk, maka kualitas kehidupan manusia juga buruk. Semakin baik kualitas spiritual, semakin baik kualitas kehidupan manusia. Kecerdasan intelektual dan kecerdasan emosional memang sangat diperlukan untuk kehidupan, tetapi dua kecerdasan ini tidak memadai bila tidak disertai oleh kecerdasan spiritual. Dalam kaitan dengan perlindungan hakhak asasi manusia, fungsi spiritulitas ditentukan oleh beberapa unsurnya yang mencakup: cinta sebagai sumber pokok makna dan kebahagiaan; kapasitas untuk hidup bermoral atau secara etis; nir-kekerasan yang mendalam; perasaan solidaritas spiritual dengan makhluk-makhluk lain.
\end{abstract}

Kata Kunci: Spiritual, manusia, hak asasi manusia

Pemeliharaan hak asasi manusia bukan persoalan hukum semata. Hak asasi manusia terkait dengan berbagai aspek kehidupan manusia. Salah satu aspek kehidupan yang paling menentukan perlindungan hak asasi manusia, yang sekaligus paling menentukan perjalanan hidup manusia, adalah aspek spiritual (wajh rūhānī). Bila kualitas spiritual manusia baik, maka kualitas kehidupan manusia juga baik. Bila kualitas spiritual manusia buruk, maka kualitas kehidupan manusia juga buruk. Semakin baik kualitas spiritual, semakin baik kualitas kehidupan manusia. Kecerdasan intelektual dan kecerdasan emosional memang sangat diperlukan untuk kehidupan, tetapi dua kecerdasan ini tidak memadai bila tidak disertai oleh kecerdasan spiritual karena kecerdasan spiritual adalah yang paling menentukan arah perjalanan hidup manusia.

Kita sering mendengar penjelasan bahwa manusia terdiri dari dua unsur: roh (rūh) dan jasad (jasad) atau jisim (jism). Roh 
dan jasad adalah kategori-kategori konseptual paling dasar dari pemikiran Islam pada umumnya. Klasifikasi konseptual dualitas dasar ini sejalan dengan klasifikasi konseptual bahwa segala sesuatu di alam semesta ini terdiri dari dua unsur atau sifat: cahaya dan kegelapan, gaib dan nyata, halus dan kasar, batin dan lahir, tinggi dan rendah, maskulin dan feminin, langit dan bumi, aktif dan pasif, dan seterusnya. Klasifikasi ini dikukuhkan oleh konsep dualistik al-Qur'an bahwa Allah adalah Yang Tampak (al-zhāhir) dan Yang Tidak Tampak (al-bāthin) (Q 57: 3), Allah telah menciptakan langit dan bumi, dan menjadikan kegelapan dan cahaya (Q 6: 1; 6: 73), dan Allah adalah yang mengetahui yang gaib dan yang nyata (Q 6: 73; 9: 94, 105).

Berbeda dengan klasifikasi konseptual dualistik ini, ada klasifikasi yang lebih lengkap, yang bisa kita sebut "klasifikasi konseptual trinalistik," yaitu bahwa manusia terdiri dari tiga unsur: roh (rūh), jiwa (nafs), dan jasad (jasad, jism). Di sini kita melihat bahwa roh menempati kedudukan tertinggi dan jasad menempati kedudukan terendah. Tempat jiwa (nafs) adalah antara roh dan jasad. Karena itu, nafs sekaligus memiliki kecenderungan jasmani, kecenderungan material, dan kecenderungan rohani, kecenderungan spiritual. Ketika unsur jasmani menguasai nafs, ia tetarik kepada kesenangan dan keuntungan duniawi. Tetapi, ketika nafs berkembang kepada tingkat lebih tinggi, dalam arti dikuasai oleh unsur rohani, ia menjadi tertarik kepada asalnya, yaitu Tuhan. Maka selalu ada tarik-menarik antara kecenderungan jasmani, yang mengarah kepada kejahatan, pada satu pihak, dan kecenderungan rohani, yang mengarah kepada kebaikan, pada pihak lain. Mana yang menang di antara dua kecenderungan ini dalam diri manusia tergantung pada mana yang lebih kuat dan berkuasa. Ketika nafs dikuasai oleh unsur rohani, yang senantiasa merindukan asalnya, yaitu Tuhan, ketika itulah spiritualitas (rūhāniyyah) menjadi pengendali perjalanan hidup manusia.

Agama atau ritual keagamaan tidak idendik dengan spiritulitas. Tidak jarang orang yang ritual keagamaannya sangat intens secara formal tetapi jauh dari spiritulitas. Agama atau ritual keagamaan adalah cara untuk mencapai spiritualitas, 
bukan spiritualitas itu sendiri. Kegagalan agama-agama terorganisir (organized religions), atau agama-agama mapan (established religions) dalam menumbuhkan dan memelihara spiritualitas telah mendorong banyak manusia modern meninggalkan agama-agama itu dan beralih kepada spiritualitas. Mereka meneriakkan slogan, "Spirituality, Yes! Organized Religion, No!" Slogan ini menyuarakan ketidakpercayaan orang-orang modern sekuler kepada agama-agama mapan, yang dianggap gagal memberikan jawaban terhadap tantangantantangan zaman modern, dan mencerminkan kecenderungan untuk menoleh kepada spiritulitas. Gerakan spiritual baru yang disebut New Age ini sangat popular di Barat.

Apa itu spiritualitas? Mahatma Gandhi, pemimpin nasionalis dan reformer sosial Hindu yang dikenal sebagai tokoh anti-kekerasan, mengatakan bahwa spiritualitas adalah hidup senantiasa dalam kehadiran Tuhan. ${ }^{1}$ Definisi Gandhi ini sangat mirip dengan definisi Roger Walsh, Profesor psikiatri, filsafat dan antropologi pada Universitas California di Irvine, bahwa spiritualitas adalah "pengalaman langsung akan yang sakral. Praktik-praktik spiritual adalah praktik-praktik yang menolong kita mengalami yang sakral - yang sentral dan esensial bagi kehidupan kita - bagi diri kita."2

Wayne Teasdale, seorang rahib Kristen dalam tradisi Dom Bede Griffiths, mengatakan bahwa spiritualitas adalah sebuah sikap batiniah dalam hubungan dengan Yang Ilahi atau Realitas Teragung (the Ultimate Reality) yang menyeru anda kepada kesadaran yang lebih tinggi. Spiritualitas mewujudkan keinginan kuat yang terdalam dan termurni kita, kerinduan yang penuh gairah kita kepada Yang Ilahi. Spiritualitas adalah kerinduan untuk bersatu dan bermesraan dengan Tuhan, dengan Realitas Teragung. Dicirikan oleh komitmen yang penuh gairah ini kepada Yang Teragung, semua spiritualitas memperoleh bentuk merangkul perjalanan spiritual, jalan kepada transformasi dan perkembangan batiniah. Setiap jenis spiritualitas membangunkan kita kepada realitas sebagaimana adanya dan kepada keadaan kita sendiri. Spiritualitas itu sendiri, sebagai dimensi terdalam kehidupan dan wujud, adalah lazim bagi semua agama. ${ }^{3}$ 
John White, seorang pembela New Age yang lahir di kota New York, mengatakan bahwa pada esensinya, spiritualitas adalah hidup benar-benar dengan tujuan menyadari Tuhan dalam setiap keadaan wujud anda - pemikiran, emosi, kata, relasi, aspirasi - pendeknya, totalitas kehidupan anda, yang benar sesuai dengan tujuannya. Pendirian ini dalam hidup adalah satu-satunya sikap yang benar-benar bisa menciptakan sebuah dunia yang lebih baik. Tidak akan pernah ada sebuah dunia yang lebih baik hingga ada penduduk yang lebih baik di dalamnya. Cara membangun penduduk yang lebih baik adalah memulai dengan diri anda sendiri dengan menyadari Tuhan. Menyadari Tuhan berarti mengetahui Tuhan pada setiap tingkat realitas dan pada setiap modus atau aspek wujud Tuhan. Jadi, spiritualitas dapat didefinisikan, tingkat demi tingkat realitas, dengan cara berikut:

Pada ranah fisis, spiritualitas adalah mengakui natur yang menakjubkan dari benda dan sumber kreatif di balik rahasia benda itu.

Pada ranah biologis, spiritualitas adalah menyadari bahwa inteligensi ilahi mendasari semua perubahan hidup dan perubahan seperti itu mengembangkan seluruh ciptaan kepada tingkat-tingkat yang lebih besar dari keseluruhan agar mengungkapkan dirinya secara sempurna.

Pada ranah psikologis, spiritualitas adalah menemukan di dalam diri anda sumber pokok makna dan kebahagiaan, yaitu cinta.

Pada ranah sosiologis, spiritualitas adalah memberikan pelayanan tanpa pamrih kepada orang-orang lain tanpa memperhatikan ras, kredo, agama, warna kulit, jender, kasta, atau kebangsaan.

Pada ranah ekologis, spiritualitas adalah menunjukkan rasa hormat kepada semua kerajaan dalam komunitas 
kehidupan - mineral, tumbuh-tumbuhan, sayur-mayur, binatang, manusia, roh, dan malaikat.

Pada ranah kosmologis, spiritualitas adalah menyatu dengan alam semesta, sejalan dengan yang tidak terbatas, yang mengalir dengan Tao.

Pada ranah teologis, spiritualitas adalah melihat Tuhan dalam segala sesuatu, semua peristiwa, semua keadaan, yang berdiam sebagai cahaya tak terbatas dan cinta tanpa syarat, dan melihat segala sesuatu, peristiwa, dan keadaan di dalam Tuhan sebagai matriks atau lautan tak bertepi yang di dalamnya alam semesta terjadi. ${ }^{4}$

Penjelasan-penjelasan di atas menunjukkan bahwa spiritualitas menekankan kehadiran Wujung Teragung (the Supreme Being), Yang Mutlak (the Absolute), Yang Transenden (the Transcendent), yang disebut Tuhan. Spiritualitas adalah pengalaman batiniah kesatuan diri seseorang dengan Tuhan. Dengan ungkapan lain, dikatakan bahwa spiritualitas adalah pengalaman batiniah kedekatan diri seseorang dengan Tuhan. Karena itu, dosa dalam pandangan ini adalah keterpisahan dari Tuhan atau keadaan jauh dari Tuhan.

Spiritualitas bukan teori, bukan pengetahuan, bukan pemikiran, bukan filsafat, dan bahkan bukan agama. Spiritualitas adalah pengalaman langsung akan Realitas Teragung, akan Yang Ilahi, yang disebut Tuhan, Allah, Brahman, Yahweh, Tao, atau nama-nama lain. Pengalaman langsung ini dicapai dengan cinta yang muncul dari hati pencinta kepada Yang Dicinta. Cinta berasal dari sumber cinta: Yang Maha Pencinta. Cinta sang hamba adalah anugerah dari Yang Maha Pencinta, yang berdiam dalam hati sang hamba. Karena itu, Dia tidak perlu dicari di tempat-tempat yang jauh seperti gua-gua, gunung-gunung, atau di ujung dunia, karena Dia ada dalam hati anda. Tepat sekali apa yang dikatakan oleh Yunus Emre, seorang bijak dan sufi dari Turki, "Ketika anda mencari Tuhan/ Carilah Dia di dalam hati anda."5 
Hak-hak asasi manusia adalah hak-hak yang secara inheren melekat dalam diri manusia, yang tanpanya manusia tidak dapat hidup sebagai manusia. Hak-hak asasi manusia didasarkan pada prinsip bahwa semua manusia memiliki kebebasan dan persamaan dalam martabat dan hak-hak tanpa memandang perbedaan apapun, seperti ras, warna kulit, jenis kelamin, bahasa, agama, pandangan politik atau yang lain, asal kebangsaan atau sosial, sifat, kelahiran, atau status lain. Di sini, "istilah hak-hak asasi manusia mengacu pada hak-hak yang diakui oleh dan didukung melalui hukum dan institusi-institusi internasional." Pasal 1.3 Piagam PPB mewajibkan semua anggotanya untuk bekerjasama memajukan dan menggalakkan perhatian pada hak-hak asasi manusia dan kebebasan-kebebasan fundamental bagi semua manusia tanpa memandang perbedaan seperti ras, jenis kelamin (atau jender), bahasa, atau agama. Tetapi piagam itu tidak mendefinisikan istilah-istilah hak-hak asasi manusia dan kebebasan-kebebasan fundamental. Tugas itu dilakukan oleh PBB dalam serangkaian deklarasi, konvensi, dan kovenan (perjanjian) yang dirancang dan disetujui sejak 1948. Dokumen-dokumen hak-hak asasi manusia PBB dan dokumendokumen regional Eropa, Amerika, dan Afrika semuanya memiliki premis yang sama bahwa ada standar-standar universal hak-hak asasi manusia yang harus ditaati oleh semua negara di dunia, atau negara-negara regional dalam hal dokumendokumen regional.

Ada perdebatan tentang universalitas sejati sebagian standar hak-hak asasi manusia, dan ada beberapa problem serius dalam penerapannya. Bagaimanapun, ini tidak berarti bahwa tidak ada standar-standar yang universal dan mengikat atau upaya-upaya pelaksanaannya harus ditinggalkan. Posisi yang diambil di sini adalah bahwa terdapat standar-standar universal tertentu hak-hak asasi manusia yang mengikat di bawah hukum internasional dan bahwa setiap upaya harus dilakukan untuk melaksanakannya dalam praktik. Dengan demikian, prinsip perhatian dan perlindungan terhadap hak-hak asasi manusia telah dideskripsikan sebagai jus cogens, yaitu prinsip yang begitu fundamental dari hukum internasional yang tidak boleh 
ditolak oleh negara-negara dengan persetujuan negara-negara itu. Tentu saja ini adalah benar untuk perhatian dan perlindungan terhadap hak-hak asasi manusia pada dasarnya.

'Abdullahi Ahmed An-Na`im, seorang pemikir Islam liberal asal Sudan, mengakui

bahwa kesulitan utama dalam membangun standar-standar universal lintas batas-batas budaya, dan khususnya agama, adalah bahwa setiap tradisi memiliki kerangka acuan internalnya sendiri karena setiap tradisi menganggap validitas aturan-aturan dan norma-normanya bersal dari simber-sumbernya sendiri. Jika suatu tradisi kultural, khususnya keagamaan, berhubungan dengan tradisi-tradisi lain juga, mungkin hubungan itu dilakukan dengan cara negatif dan barangkali dengan cara permusuhan. Menuntut loyalitas dan kepatuhan anggota-anggotanya, sebuah tradisi kultural atau keagamaan biasanya menegaskan keunggulan dirinya atas tradisi-tradisi lain.

Namun demikian, ada suatu prinsip normatif umun yang dimiliki bersama oleh semua tradisi kultural besar yang, jika ditafsirkan dengan suatu cara yang tercerahkan, mampu menopang standar-standar universal hak-hak asasi manusia. Itu adalah prinsip bahwa "seseorang harus memperlakukan orangorang lain sebagaimana ia menginginkan diperlakukan oleh mereka." Kaidah emas ini sebagai prinsip "resiprositas" (perlakuan timbal-balik) dimiliki bersama oleh semua tradisi keagamaan besar dunia. Lebih dari itu, kekuatan moral dan logis proposisi ini dengan mudah dihargai oleh semua umat manusia dari tradisi kultural apapun dan dari keyakinan filosofis apapun. ${ }^{6}$

Siapa pun yang ingin hidup damai bersama orang-orang lain harus mematuhi Kaidah Emas (The Golden Rule) ini, yang berbunyi: "Perlakukanlah orang-orang lain sebagaimana Anda menginginkan diperlakukan oleh mereka." Nabi Muhammad saw: "Tidak seorang pun di antara kamu beriman kecuali dia mencintai untuk saudaranya apa yang dia cintai untuk dirinya sendiri" (Hadis). Yesus Kristus: "Segala sesuatu yang kamu kehendaki supaya orang-orang lain perbuat kepadamu, perbuatlah demikian itu kepada mereka" (Matius 7:12). Hillel, seorang guru Yahudi: "Apa yang kamu benci, janganlah kamu perbuat kepada orang-orang lain." Seruan dari sebuah kitab suci 
Hindu: "Ini adalah sejumlah seluruh kewajiban: janganlah perbuat sesuatu kepada orang-orang lain yang, bila itu diperbuat kepadamu, akan menyebabkan kamu sakit" (Mahabharata). Sang Buddha: "Janganlah menyakiti orang-orang lain dengan yang menyakiti dirimu." Khonghucu: "Apa yang tidak kamu inginkan untukmu, janganlah melakukannya kepada orangorang lain" (Analek 15:23).

Ada dua pengendali kehidupan manusia: pengendali dari luar diri manusia dan pengendali dari dalam diri manusia. Pengendali dari luar diri manusia meliputi perintah-perintah, para penegak perintah-perintah itu, keluarga dan masyarakat. Perintah-perintah harus dipatuhi oleh manusia agar mereka hidup damai, sejahtera, dan bahagia. Perintah-perintah dapat dibagi menjadi dua jenis: perintah-perintah untuk melakukan sesuatu dan perintah-perintah untuk tidak melakukan sesuatu. Perintah-perintah jenis pertama tetap disebut "perintahperintah," sedangkan perintah-perintah jenis kedua disebut "larangan-larangan." Semua perintah, yang mencakup jenis pertama dan jenis kedua, ditetapkan oleh dan dalam peraturanperaturan atau hukum-hukum, yang dalam Islam disebut "syariah" (syarī'ah). Perlindungan hak-hak asasi manusia sangat jelas tercermin dalam bentuk "larangan-larangan" yang biasanya dinyatakan dengan kata "Jangan" seperti "Jangan membunuh!", "Jangan mengambil hak orang lain!", dan "Jangan berlaku zalim!" Larangan-larangan itu atau perbuatan-perbuatan terlarang yang mendapat sanksi azab di akhirat adalah dosa. Hidup adalah salah satu hak asasi manusia paling berharga yang dianugerahkan oleh Tuhan. Karena itu, membunuh dilarang oleh syariah. Larangan membunuh adalah bentuk perlindungan hak untuk hidup, salah satu hak asasi manusia.

Para pelaku perbuatan kriminal akan mendapatkan sanksi melalui proses hukum. Besarnya sanksi tergantung pada besarnya perbuatan kriminal yang dilakukan. Selain sanksi hukum formal, ada juga sanksi sosial dari masyarakat yang tidak kalah beratnya. Bila penegakan hukum benar-benar dilakukan dengan tegas, orang yang berniat melakukan perbuatan kriminal seperti membunuh dan merampok, yang merupakan pelanggaran 
hak asasi manusia, akan berpikir panjang apakah ia akan melakukannya atau tidak. Di negara-negara yang penegakan hukumnya kuat sekalipun, pelanggaran hak-hak asasi manusia tetap terjadi. Pengendali dari luar dapat dijebol oleh hawa nafsu liar yang tidak terkendali.

Pengendali dari dalam diri manusia adalah roh $(r \bar{u} h)$, yang menjadi khalifah, raja, atau pengatur bagi kerajaan manusia di dalam dirinya. Kerajaan manusia di dalam dirinya adalah kerajaan hakiki yang menentukan perjalanan kerajaan manusia di dunia. Roh sebagai khalifah yang menjalankan pemerintahan atas kerajaan manusia di dalam dirinya sendiri menentukan perjalanan kerajaan manusia di atas bumi. Allah telah menjadikan manusia sebagai khalifah-Nya di atas bumi karena kelebihan dan keistimewaannya di banding dengan makhlukmakhluk lain. Manusia adalah khalifah Allah yang bertugas memimpin dunia sebagai kerajaannya. Tetapi kerajaan hakikinya adalah kerajaan di dalam dirinya sendiri. Bumi hakikinya adalah bumi tubuhnya sendiri yang lengkap dan sempurna dengan bagian-bagian dan penghuni-penghuni yang dapat dikelola dengan pemerintahan yang dituntun oleh Allah. Bagaimana mungkin manusia menjadi khalifah Allah di atas bumi bila ia sendiri tidak mampu menjadi khalifah di atas bumi dirinya sendiri?

Ibn 'Arabi melukiskan tubuh manusia bagai kota dengan segala yang ada di dalamnya. Allah mendirikan kota untuk menjadi tempat tinggal sang khalifah bersama rakyat dan para pegawai pemerintahannya. Ketika Allah menyelesaikan pembangunan kota itu, Dia menentukan tempat khusus untuk sang khalifah. Tempat khusus itu adalah hati (qalb). Allah berfirman melalui hadis qudsi: "Langit dan bumi-Ku tidak mampu meliputi-Ku, tetapi hati hamba-Ku yang mukmin meliputi-Ku." Nabi bersabda: "Sungguh, Allah tidak memandang pada parasmu dan tidak pula pada perbuatanmu, tetapi pada hatimu." Allah menjadikan roh (al-rūh $\underline{h})$ sebagai khalifah atas tubuh. Maka yang bertanggungjawab atas tubuh bukanlah hati nabati, tetapi adalah roh. Ibn 'Arabi membedakan hati nabati dan hati rohani yang disebut qalb, yang didalam alQur'an dikatakan, 'Sebenarnya bukan mata mereka yang buta, 
tetapi yang buta adalah hati di dalam dada" (Q 22: 46). Nabi Muhammad saw berkata: "Ada sepotong daging di dalam tubuh manusia. Jika ia baik, maka seluruh tubuh baik. Jika ia rusak, maka seluruh tubuh juga rusak. Sepotong daging itu adalah hati [qalb]." Jika pemimpin baik, rakyatnya juga baik. Jika ia rusak, rakyatnya juga rusak. Pemimpin itu adalah roh.

Allah juga mendirikan taman di bagian tertinggi kota itu, yang dinamakan dimāgh (otak). Dia membuka empat jendela besar untuk mengawasi kerajaan itu. Empat jendela itu adalah telinga, mata, hidung, dan mulut. Dia juga membangun di depan taman itu tempat penyimpanan yang disebut "tempat penyimpanan khayal" (khazānat al-khayāl). Di taman itu Tuhan membangun tempat penyimpanan pikiran dan tempat penyimpanan hapalan. Allah menjadikan taman kota yang disebut "otak" itu sebagai tempat tinggal perdana menteri yang disebut "akal" ('aql). Allah juga menjadikan nafs (diri/jiwa) sebagai tempat perubahan dan pembersihan, dan tempat perintah dan larangan. Roh menikahi nafs dan pernikahan ini melahirkan tubuh. Selain itu Allah juga menciptakan kepala suku yang disebut "hawa nafsu" (hawa) dan menteri yang disebut "syahwat" (syahwah).

Nafs ini sering digoda dan dirayu oleh hawa nafsu dan syahwat sehingga jatuh ke dalam pelukan hawa nafsu dan syahwat. Akal tidak mencegahnya, bahkan menutupinya agar Khalifah tidak mengetahui bahwa isterinya telah dirampas. Roh tidak bisa berbuat apa-apa. Ketika nafs sadar bahwa ia tertipu, maka ia mulai menyesali perbuatannya (al-nafs al-lawwämah). Ia semakin sadar dan terilhami untuk berbuat baik (al-nafs almulhamah). Keadaan itu membuat ia menjadi tenang (al-nafs almuthma'innah) karena ia telah bersatu kembali dengan suaminya (roh) atas perolongan Allah.

Sufi terbesar dari Andalusia ini menasehatkan agar Anda berteman dengan orang-orang yang beriman, berbuat ihsan, adil dan patuh pada hukum Allah. Pada hakikatnya, iman, ihsan, keadilan, dan kepatuhan adalah teman-teman yang baik. Karena itu, berakhlak dengan sifat-sifat itu adalah jalan keselamatan bagi manusia di dunia dan akhirat. Maka beliau mengingatkan 
agar Anda berhati-hati terhadap teman-teman yang jahat karena mereka berbahaya bagi diri Anda. Mereka itu mungkin menjadi penyebab keruntuhan kerajaan Anda dan kehancuran negeri wujud Anda. Teman yang jahat itu tidak jauh dari diri Anda. Ia ada di dalam diri Anda sendiri. "Teman (al-qarīn) dalam [diri] Anda itu adalah hawa nafsu Anda (hawāka)." Dikatakan, "Perangilah hawa nafsu Anda (jāhid hawāka), karena ia adalah musuh Anda yang paling besar." Allah berfirman, "Wahai orang-orang beriman! Perangilah orang-orang kafir yang dekat dengan kamu" (Q 9: 123). Orang kafir itu adalah "orang kafir yang paling dekat dengan kamu (aqrab al-kuffār ilayka)."

Peringatan Ibn 'Arabi ini tampaknya diinspirasi oleh perkataan Nabi Muhammad saw sepulang dari Perang Badar. Beliau berkata: "Kita telah kembali dari jihad yang lebih kecil kepada jihad yang lebih besar." Lalu para sahabat bertanya kepada beliau: "Wahai Rasulullah, apa jihad yang lebih besar itu?" Rasulullah menjawab: "Jihād nafs" ("Jihad melawan diri sendiri”). Pada sebagian nash (teks), ungkapan yang digunakan adalah "mujāhadat al-nafs" (yang juga berarti "melawan diri"). Di dalam beberapa kitab tasawuf, ungkapan yang digunakan bukan "jihād al-nafs," tetapi adalah "mukhālafat al-nafs" (yang juga dapat diterjemahkan dengan "melawan atau menentang diri"). Ungkapan "mukhālafat al-nafs" ditemukan, misalnya, dalam kitab Al-Risālah al-Qusyairiyyah (karya 'Abd al-Karim al-Qusyayri) dan dalam Al-Futūhāat al-Makkiyyah (karya Ibn 'Arabi). Kata nafs berarti jiwa, diri, ego, atau hawa nafsu.

Jadi jihad terbesar adalah melawan diri sendiri, memerangi diri sendiri, dan bahkan meninggalkan diri sendiri. Diri yang harus dilawan, diperangi, atau ditinggalkan adalah diri yang memiliki kecenderungan pada kejahatan, yang disebut al-nafs al-ammārah (diri/jiwa yang memerintah kepada kejahatan). Meninggalkan diri adalah pintu gerbang untuk berakhlak dengan akhlak Allah, yang berarti berakhlak dengan nama-nama-Nya, atau sifat-sifat-Nya. Inilah jalan yang benar menggapai Sang Kebenaran (al- $\underline{H} a q q)$, sumber segala kebenaran.

Berakhlak dengan akhlak Allah adalah jalan menuju Allah, Sang Kebenaran, yang harus dilakukan dengan meninggalkan diri. Ibn 'Arabi mengisahkan pengalaman spiritual Abu Yazid al- 
Bistami mencari cara mendekatkan diri kepada Tuhan, sebagai berikut:

Pada waktu yang lain, Abu Yazid berkata kepada Rabbnya: "Dengan apa aku mendekatkan diri kepada-Mu?" Sang Kebenaran (al- $\underline{H a q q}$ ) menjawab: "Tinggalkan dirimu dan datanglah [kepada-Ku]!" Ketika ia meninggalkan dirinya, ia meninggalkan sifat kehambaannya, karena kehambaan ('ubüdiyyah) identik dengan kejauhan dari Ketuanan (siyādah), dan hamba jauh dari Tuan. Maka dalam kerendahan dan kefakiran, ia mencari kedekatan dengan kehambaan, sedangkan dalam meninggalkan diri ia mencari kedekatan dengan berakhlak dengan akhlak Allah. Itu adalah dengan apa yang menjadi kesatu-paduan. ${ }^{8}$

"Berakhlak dengan akhlak Allah" dengan tujuan mendekatkan diri kepada-Nya, sebagaimana dialami Abu Yazid, harus dimulai dengan meninggalkan diri. Dapat pula dikatakan bahwa meninggalkan diri adalah langkah awal berakhlak dengan akhlak Allah. Berakhlak dengan akhlak Allah adalah tasawuf, dan akhlak Allah adalah al-Qur'an, sebagaimana ditemukan pada Muhammad.

Ibn 'Arabi' melukiskan bahwa pasukan kerajaan bagaikan tiang penopang tenda kerajaan dan pasak pengukuh yang dipegang orang. Kerajaan itu adalah laksana rumah, yang mesti ditopang empat tiang penyangga. Empat tiang penyangga itu, yang terbuat dari sifat-sifat manusia, adalah kekuatannya. Angka Empat adalah hakikat dasar bilangan; di dalamnya ada angka Tiga. Jika angka Tiga kita tambahkan kepada angka Empat, hasilnya adalah Tujuh. Di dalam angka Empat ada pula angka Dua. Jika angka Dua kita tambahkan kepada angka Tujuh, hasilnya adalah Sembilan. Yang tersisa setelah angka Dua adalah angka Satu. Jika angka Satu kita tambahkan kepada angka Sembilan, hasilnya adalah Sepuluh. Inilah bilangan dasar. Tidak ada angka lain yang jika ditambahkan menjadi Sepuluh kecuali Empat tambah Tiga, tambah Dua, tambah Satu, yang pada gilirannya sama dengan angka Empat. Jadi angka Sepuluh ada di dalam angka Empat. 
Angka Empat dipilih karena mengandung kearifan (hikmah), yang memiliki kekuatan-kekuatan ilahi. Angka Empat menyelenggarakan tugas kerajaan, dan karena itu penyangga takhta adalah delapan tiang, sebagaimana dikatakan Nabi Muhammad saw: "Langit disangga oleh delapan tiang, tetapi di zaman kita hanya ada empat tiang." Allah berirman: "Pada hari itu delapan malaikat menjunjung Takhta Tuhan di atas mereka" (Q 69: 17). Khalifah Allah memiliki empat unsur dasar dalam alam materi, yaitu tanah, air, udara, dan api. Empat unsur ini pula yang menjadi dasar seluruh alam. Empat unsur dasar ini merupakan gerbang menuju Empat Puluh.

Empat adalah arah-arah yang memasuki kerajaan manusia. Semua pengaruh yang menimbulkan kerusakan dalam kehidupan manusia berasal dari "empat arah": kanan, kiri, depan, dan belakang. Allah berfirman: "Kemudian aku [Iblis] akan mendatangi mereka dari depan, dari belakang, dari kanan, dan dari kiri mereka" (Q 7: 17). Tidak ada arah lain yang menjadi sumber godaan Iblis. Yang di bawah adalah arah yang memanggil manusia, sedang yang di atas adalah tempat jalan turunnya Tuhan (al-tanazzul al-ilāhì), yang dilarang untuk didekati oleh manusia, karena itu adalah jalan qadla dan qadar.

Manusia sebagai Tuan Yang Mulia diperintahkan untuk berhati-hati menghadapi empat arah ini karena memiliki kekuatan untuk merusak. Manusia harus menempatkan empat kesatuan pasukan dengan empat jenderalnya untuk menjaga dan melindungi kerajaan, nyawa, dan kedamaian. Musuh hanya dapat memasuki wilayah kerajaan jika empat arah ini tidak dijaga. Strategi perang adalah: menempatkan rasa takut (khawf) kepada Allah di arah kanan, menempatkan harapan (rajā') kepada Allah di arah kiri, menempatkan ilmu ('ilm) di arah depan, dan menempatkan tafakur (tafakkur) di arah belakang.

Roh sebagai khalifah kerajaan manusia di dalam dirinya adalah pengendali diri manusia yang jauh lebih efektif dari pada pengendali dari luar dirinya dalam mengarahkan perjalanan hidupnya. Pengendali dari dalam diri pasti lebih kokoh dari pada pengendali dari luar diri dalam melindungi hak-hak asasi manusia. Pengendalian dari dalam diri ini adalah fungsi spiritualitas. Dalam kaitan dengan perlindungan hak-hak asasi 
manusia, fungsi spiritulitas ditentukan oleh beberapa unsurnya yang mencakup: cinta sebagai sumber pokok makna dan kebahagiaan; kapasitas untuk hidup bermoral atau secara etis; nir-kekerasan yang mendalam; perasaan solidaritas spiritual dengan makhluk-makhluk lain, termasuk bumi; praktik spiritual dan pengetahuan-diri yang komprehensif; kesederhanaan gaya hidup; pelayanan tanpa pamrih; dan aksi profetik. Spiritualitas dengan unsur-unsur universalnya ini berfungsi preventif melindingi hak-hak asasi.

Allah lebih mengetahui mana yang benar.

${ }^{1}$ Dikutip oleh R.R. Diwakar, "Gandhi is Spirituality in Action," Gandhi Marg, 6/11 (Februari 1985), yang kemudian dikutip oleh Gedong Bagoes Oka, "Spiritualitas Baru dalam Agama Hindu," dalam Spiritualitas Baru: Agama dan Aspirasi Rakyat, Seri Dian/ Interfidei 2/ Tahun 1 (Yogyakarta: Institut Dian/ Interfidei, 1994), h. 25.

${ }^{2}$ Roger Walsh, Essensial Spirituality: The 7 Central Practices to Awaken Heart and Mind (New York: John Wiley \& Sons, Inc., 1999), h. 3.

${ }^{3}$ Teasdale, "Elements of a Universal Spirituality," dalam Joel D. Beversluis, Project Editor, A SourceBook for Earth's Community of Religions, Revisd Edition (Grand Rapids, Michigan: CoNexus Press SourceBook Project, New York: Global Education Associates, 1995), h. 145.

${ }^{4}$ John White, The Meeting of Science and Spirit: Guidelines for a New Age (New Delhi: HarperCollins, 1997), h. 239-40. Teks kutipan di atas dalam bahasa Inggrisnya adalah sebagai berikut:

In physical terms, spirituality is recognizing the miraculous nature of matter and the creative source behind the mystery of matter.

In biological terms, spirituality is realizing that a divine intelligence underlies all life-change and that such change is evolving all creation to ever greater degrees of wholeness in order to perfectly express itself.

In psychological terms, spirituality is discovering within yourself the ultimate source of meaning and happiness, which is love.

In sociological terms, spirituality is giving selfless service to others, regardless of race, creed, color, gender, caste, or nationality.

In ecological terms, spirituality is showing respect for all the kingdoms in the community of life - mineral, vegetable, animal, human, spirit, and angelic.

In cosmological terms, spirituality is being at one with the universe, in tune with the infinite, flowing with the Tao. 
In theological terms, spirituality is seeing God in all things, all events, and all circumstances, indwelling as infinite light and unconditional love, and seeing all things, events, and circumstances in God as the matrix or infinite ocean in which the universe occurs.

${ }^{5}$ Dikutip oleh Walsh, Essensial Spirituality, h. 1.

6 'Abdullahi Ahmed An-Na 'im, "Shari'a and Basic Human Rights Concerns," dalam Charles Kurzman, ed., Liberal Islam: A Sourcebook (New York \& Oxford: Oxford University Press, 1998), h. 222-225.

${ }^{7}$ Ibn 'Arabi, Al-Tadbīrāt al-Ilāhiyyah, h. 150-51.

${ }^{8} \mathrm{Ibn}$ 'Arabi, al-Futūhāt al-Makkiyyah, 4: 285.

${ }^{9}$ Ibn 'Arabi, Al-Tadbīrāt al-Ilāhiyyah, h. 192-95.

\section{REFRENSI}

Diwakar, R.R., "Gandhi is Spirituality in Action," Gandhi Marg, 6/11 (Februari 1985), yang kemudian dikutip oleh Gedong Bagoes Oka, "Spiritualitas Baru dalam Agama Hindu," dalam Spiritualitas Baru: Agama dan Aspirasi Rakyat, Seri Dian/ Interfidei 2/ Tahun 1, Yogyakarta: Institut Dian/ Interfidei, 1994,

'Arabi, Ibn, Al-Tadbīrāt al-Ilāhiyyah, -----------, al-Futūhāt al-Makkiyyah,

An-Na 'im, Abdullahi Ahmed, "Shari'a and Basic Human Rights Concerns," dalam Charles Kurzman, ed., Liberal Islam: A Sourcebook, New York \& Oxford: Oxford University Press, 1998

Teasdale, "Elements of a Universal Spirituality," dalam Joel D. Beversluis, Project Editor, A SourceBook for Earth's Community of Religions, Revisd Edition (Grand Rapids, Michigan: CoNexus Press - SourceBook Project, New York: Global Education Associates, 1995

White, John, The Meeting of Science and Spirit: Guidelines for a New Age, New Delhi: HarperCollins, 1997 